\title{
FLAVONOIDS OF THE LEAVES OF Rhamnus pallasii
}

T. S. Zurabishvili and I. I. Moniava

UDC 547.972

From the air-dry leaves of Rhamnus pallasii F. et M. growing in Tbilisi the flavonoids were extracted with $80 \%$ methanol. The ethanol was evaporated from the extract under vacuum, and the aqueous liquid was purified with chloroform and was chromatographed on a column of polyamide sorbent. The column was washed with chloroform and with mixtures of ethanol and chloroform with gradually increasing concentrations of ethanol. Three individual flavonoids $-1,2$, and 3 - were obtained.

Substance 1 , with the composition $\mathrm{C}_{15} \mathrm{H}_{10} \mathrm{O}_{6}, \mathrm{mp} 275-277^{\circ} \mathrm{C}$ was identified by its $\mathrm{R}$ and $\mathrm{UV}$ spectra and by its behavior on paper chromatography as 3,4',5,7-tetrahydroxyflavone or kaempferol.

Substance 2 , with the composition $\mathrm{C}_{16} \mathrm{H}_{12} \mathrm{O}_{7}, \mathrm{mp} 303-305^{\circ} \mathrm{C}$ was identified similarly as $3,4^{\prime} 5,7$-tetrahydroxy-3'-methoxyflavone, or isorhamnetin.

Substance 3 with the composition $\mathrm{C}_{15} \mathrm{H}_{10} \mathrm{O}_{7}$, mp $310-313^{\circ} \mathrm{C}$ was characterized as $3,3^{\prime}, 4^{\prime}, 5,7$-pentahydroxyflavone, or quercetin [1-3]. It is significant that in the leaves of Rhamnus pallasii the flavonoids are found only in the form of the free aglycones.

\section{LITERATURE CITED}

1. V. S. Batyuk and A. F. Kol'tsova, Khim. Prirodn. Soedin., 121 (1969).

2. A. P. Prokopenko, V. I. Spiridonov, V. I. Litvinenko, and V. T. Chernobai, Khim. Prirodn. Soedin., 649 (1972).

3. H. Strzelecka and J. Malinowski, Acta Pol. Pharm., 29, 417 (1972).

I. G. Kutateladze Institute of Pharmacochemistry, Academy of Sciences of the Georgian SSR. Translated from Khimiya Prirodnykh Soedinenii, No. 2, p. 254, March-April, 1974. Original article submitted November 15, 1973.

(c) 1975 Plenum Publishing Corporation, 227 West 17th Street, New York, N.Y. 10011. No part of this publication may be reproduced, stored in a retrieval system, or transmitted, in any form or by any means, electronic, mechanical, photocopying, microfilming, recording or otherwise, without written permission of the publisher. A copy of this article is available from the publisher for $\$ 15.00$. 